\title{
Role of Lamellae Morphology on the Microstructural Development and Mechanical Properties of Small-Particle Plasma-Sprayed Alumina
}

\author{
Rodney W. Trice* and K. T. Faber \\ Department of Materials Science and Engineering, Robert R. McCormick School of Engineering and Applied Science, \\ Northwestern University, Evanston, Illinois 60208
}

The influence of spray parameters on the microstructure and flexural strength of plasma-sprayed alumina was investigated. Coatings were applied using a small-particle plasma spray (SPPS) method, which is a recently patented process that allows submicrometer-sized powders to be sprayed. Using identical starting powders, coatings that were produced using two distinctly different spray conditions exhibited significant differences in both microstructure and strength. Scanning electron microscopy investigations of single lamellae (or splats) revealed that, for one spray condition, melted alumina particles will splash when they contact the substrate. The morphology of the splats that comprised the subsequent layers of the coating also were highly fragmented and thinner than lamellae formed under "nonsplashing" spray conditions. The surface roughness was strongly dependent on the morphology of the lamellae; increased roughness was noted for fragmented splats. Thick coatings that were comprised of splashed splats developed a unique microstructural feature that was responsible for the observed increase in roughness. These microstructural differences greatly influenced the flexure strength, which varied from $75 \pm 21 \mathrm{MPa}$ for the nonsplashing spray condition to $17 \pm 2.4 \mathrm{MPa}$ for the "splashing" condition.

\section{Introduction}

A LTERNATE coatings currently are being investigated as a possible replacement for electroplating technologies and toxic materials that present an environmental hazard. ${ }^{1}$ Dense, impermeable, and inert plasma-sprayed or high-velocity oxygen/fuel (HVOF) coatings, which are often comprised of alumina, have been suggested as replacement materials. These "all-dry" coatings have no toxic liquid waste and are being specifically tailored for corrosion and wear protection. ${ }^{2,3}$ Although conventional plasmasprayed coatings are neither particularly dense nor impermeable, a recently patented spray process - small-particle plasma spray (SPPS) - offers improvements in these areas. ${ }^{4}$ Using an angled, externally mounted powder injector, small-diameter powders can be placed into cooler regions of the hot plasma in a manner such that they are not vaporized. A schematic of the injector, relative to the torch, is shown in Fig. 1. Using this process, powders as small as $50 \mathrm{~nm}$ have been sprayed, in comparison to the $40-60 \mu \mathrm{m}$ powders that normally are required using traditional plasma-spray processes. Recent work has shown that SPPS alumina can protect an underlying low-alloy steel substrate from corrosive media. ${ }^{5}$

J. L. Smialek-contributing editor

Manuscript No. 189647. Received January 4, 1999; approved September 2, 1999. Supported by the "Environmentally Compliant Coatings for Wear and Corrosion Control" program of the U.S. Air Force Office of Scientific Research, under Contract No. F49620-96-1-0298.

${ }^{*}$ Member, American Ceramic Society.
Plasma-sprayed coatings are assembled from lamellae or "splats" that result from the collision of molten powders with a substrate. The manner in which these splats are stacked atop each other during each pass of the torch determines the amount and type of porosity, as well as other microstructural defects in the coating. These defects, in turn, ultimately will influence the mechanical properties (strength and modulus) of the coating. However, the morphology of the splat itself is more fundamental to the integrity of a coating than the stacking of the splats. Thus, an understanding of how the melted particles interact with the substrate or previously laid splats will give insight into the characteristics of the coating and its microstructure.

Previous work has focused on the interaction of the melted particle with the substrate, including its spreading and solidification. ${ }^{6-10}$ As such, researchers have examined the effects of particle viscosity, ${ }^{11,12}$ velocity, ${ }^{13-17}$ and temperature ${ }^{17,18}$ on splat morphology. Studies also have focused on the influence of the substrate on splat morphology; these studies included the effects of surface roughness, ${ }^{12,13,19}$ temperature, ${ }^{13,15,20-22}$ and material type. ${ }^{13,23}$ To date, however, few studies ${ }^{15,24}$ have been performed that relate the integrity of the individual splats to the physical and mechanical properties of the resulting coating. In the research that is reported here, the properties of individual splats have been correlated with the microstructure, surface roughness, and flexural strength of SPPS alumina coatings.

\section{Experimental Procedure}

\section{(1) Sample Fabrication}

The plasma-spraying equipment that was used to fabricate specimens in this study included a control system (Model

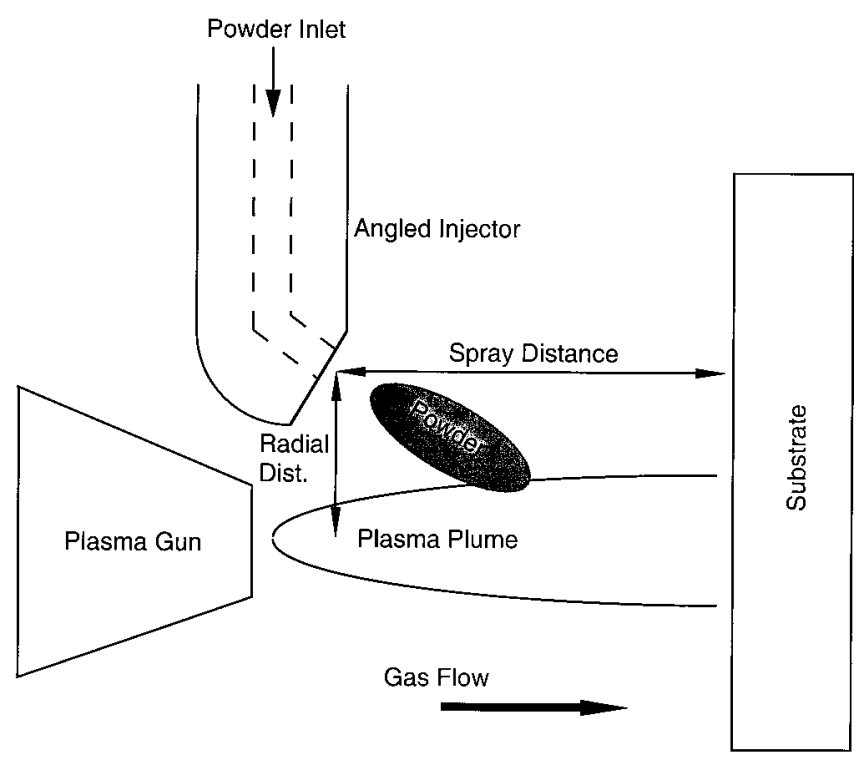

Fig. 1. Schematic of the small-particle plasma-spray (SPPS) injector; the injector has been enlarged to show detail. 
Table I. Overview of Relevant Spray Parameters for Coatings $A$ and $B$

\begin{tabular}{cccccc}
\hline $\begin{array}{c}\text { Coating } \\
\text { designation }\end{array}$ & $\begin{array}{c}\text { Power } \\
(\mathrm{kW})\end{array}$ & $\begin{array}{c}\text { Spray } \\
\text { distance }(\mathrm{cm})\end{array}$ & $\begin{array}{c}\text { Radial distance } \\
(\mathrm{mm})\end{array}$ & \multicolumn{2}{c}{ Gas flow $(\mathrm{slm})$} \\
\hline A & 35 & 7 & 7 & 35 & 5 \\
B & 45 & 6 & 6 & 45 & 7 \\
\hline
\end{tabular}

The following spray parameters were held constant: secondary gas flow, 11 standard liters of hydrogen per minute $\left(11 \mathrm{H}_{2}\right.$ slm $)$; air jet and vibrator pressure, 48 $\mathrm{psi}$; and robot speed, $350 \mathrm{~mm} / \mathrm{s}$. ${ }^{*}$ The primary gas was argon.

A-3000S, Plasma Technik, Switzerland) with an F4 gun. The gun assembly was mounted on a seven-axis robot (Model IRB 2000, ASEA Brown and Boveri, Zurich, Switzerland). All the samples were sprayed using the SPPS method. $\mathrm{Al}_{2} \mathrm{O}_{3}$ powders nominally 9 $\mu \mathrm{m}$ in size (Product HP 1110, Praxair Powder, Indianapolis, IN) were used for the current research. The powder was fed into the SPPS injector using a twin ten-disk feeder (Plasma-Technik). $\mathrm{X}$-ray diffraction (XRD) data indicated that the starting powder was $\alpha-\mathrm{Al}_{2} \mathrm{O}_{3}$ (JCPDS ${ }^{\dagger}$ File Card No. 10-173).

Substrates of 1018 steel initially were sandblasted with 220 grit alumina, followed by an ultrasonic cleaning in propanol for 10 min. These substrates were not preheated before spraying. Two different spray conditions were investigated in this research, as shown in Table I. Differences in power, primary gas flow, spray distance, and radial distance are expected to most influence the coating properties. The spray distance was measured from the center hole of the injector to the substrate, and the radial distance was defined as the distance from the injector to the center line of the plume (see Fig. 1). A scanning-type program, with a 3-mm drop between passes and a torch raster speed of $350 \mathrm{~mm} / \mathrm{s}$, was used to spray the alumina. Cooling jets, at a pressure of $0.33 \mathrm{MPa}$, were aimed at the front and back of the substrate during spraying. The deposition rate was $\sim 5 \mu \mathrm{m}$ per pass.

A single scan of the torch over a polished substrate was used to isolate individual lamellae for characterization. The processing parameters for single-splat production were identical to those described in Table I, with the exceptions that the scanning speed was $1 \mathrm{~m} / \mathrm{s}$ and the powder disk feed rate was slowed from 3 to 0.1 (relative units). These processing changes were expected to result in splats that were representative of those found in thicker coatings.

\section{(2) Physical and Mechanical Testing}

Two coatings were studied, which were termed coatings A and B. The bulk densities of coatings A and B were $3.26 \pm 0.01$ and $3.33 \pm 0.01 \mathrm{~g} / \mathrm{cm}^{3}$, respectively, as determined by the immersion method. $^{25}$ To assess the percent theoretical density of each coating, the phases and amounts of the as-sprayed coatings were determined via XRD. Only $\gamma-\mathrm{Al}_{2} \mathrm{O}_{3}$ and $\alpha-\mathrm{Al}_{2} \mathrm{O}_{3}$ were observed, and the amounts of each phase were determined experimentally by generating a calibration curve. ${ }^{26}$ In these experiments, mixtures with known amounts of both phases, along with pure samples of both $\gamma-\mathrm{Al}_{2} \mathrm{O}_{3}$ and $\alpha-\mathrm{Al}_{2} \mathrm{O}_{3}$, were evaluated using XRD. Then, the integrated intensity of the diffracted (113) peak of $\alpha-\mathrm{Al}_{2} \mathrm{O}_{3}$ for each mixed sample was divided by the integrated intensity of pure $\alpha-\mathrm{Al}_{2} \mathrm{O}_{3}$ diffracted from the same plane. In this manner, the peak

${ }^{\dagger}$ Joint Committee for Powder Diffraction Standards, Swarthmore, PA (now International Centre for Diffraction Data (ICDD), Newtown Square, PA). ratio of $\alpha-\mathrm{Al}_{2} \mathrm{O}_{3}$ diffracted from the (113) versus the weight fraction of $\alpha-\mathrm{Al}_{2} \mathrm{O}_{3}$ was determined. Subsequent testing of coatings $\mathrm{A}$ and $\mathrm{B}$ revealed more $\alpha-\mathrm{Al}_{2} \mathrm{O}_{3}$ in coating $\mathrm{A}$, as indicated in Table II. The reasons for these differences will be discussed later in this paper. Assuming densities of 3.65 and $4.0 \mathrm{~g} / \mathrm{cm}^{3}$ for the $\gamma-\mathrm{Al}_{2} \mathrm{O}_{3}$ and $\alpha-\mathrm{Al}_{2} \mathrm{O}_{3}$ phases, respectively, theoretical densities of $\sim 3.69$ and $3.68 \mathrm{~g} / \mathrm{cm}^{3}$ were calculated for coatings A and B, respectively. Coating A was observed to have greater total porosity than coating $\mathrm{B}$, as determined via the immersion method; this trend is indicated in Table II.

Cross sections of coatings $\mathrm{A}$ and $\mathrm{B}$ were polished and etched for 5 min in concentrated $\mathrm{H}_{2} \mathrm{SO}_{4}$ at $210^{\circ} \mathrm{C}$. The acid etch revealed the microstructure of the coatings; the individual splats and the alumina grains within each splat both were visible.

Surface roughness measurements, which were made with a profilometer (Mitutoyo, Tokyo, Japan) were conducted on the as-sprayed coatings. Coatings of different thicknesses were sprayed to evaluate the effect of this parameter on the surface roughness. An average of six measurements was used for each coating.

Free-standing four-point flexure bars were fabricated by spraying coatings $\sim 1 \mathrm{~mm}$ thick on steel substrates, followed by a combination of chemical dissolution and mechanical removal of the substrate. Individual bars were $0.7 \mathrm{~mm}$ thick, $3 \mathrm{~mm}$ wide, and $25 \mathrm{~mm}$ long. The inner and outer spans were 10 and $20 \mathrm{~mm}$, respectively. No polishing was performed on the coatings before testing, because of their fragility; however, grinding always was performed parallel to the applied tensile stresses. The samples were oriented in the loading fixture such that the tensile surface represented the exterior surface of the coating. Five replicates were tested for each condition.

\section{Results and Discussion}

\section{(1) Microstructure of Individual Splats}

A scanning electron microscopy (SEM) micrograph of a single splat formed from coating A spray parameters is shown in Fig. 2(a). Lamellae sprayed under these conditions were typically 10 $\mu \mathrm{m}$ in diameter and coherent in appearance; significant pullback of the splat edge is observed. A single splat formed from coating B spray parameters is shown in Fig. 2(b). Under these conditions, the splats were $\sim 30 \mu \mathrm{m}$ in diameter. Cracks were more likely to be observed in the coating B splats, in comparison with splats sprayed with coating A parameters.

Insight into the physical properties that influence the interaction of a molten droplet with a substrate have been developed by Madjeski. ${ }^{6}$ In this model, the degree of flattening of a spherical melted particle as it strikes a smooth substrate is given as

$$
\frac{D}{d}=1.29\left(\frac{\rho d v}{\eta}\right)^{0.2}
$$

where $D$ is the final splat diameter, $d$ the diameter of the melted particle, $\rho$ the density of the drop at impact, $v$ the velocity of the melted particle at impact, and $\eta$ the viscosity of the particle. Application of this equation to plasma-sprayed alumina has given values for $D / d$ that are consistent with experimental observations. ${ }^{7}$ The density of alumina at its melting temperature is $3.05 \mathrm{~g} / \mathrm{cm}^{3}$. Typical velocities for plasma-sprayed particles are in the range of $100-400 \mathrm{~m} / \mathrm{s}$; however, the small particle sizes presently used may result in increased velocity. ${ }^{13}$ The viscosity of melted alumina ranges from $0.15 \mathrm{P}$ at $2500^{\circ} \mathrm{C}$ to $0.5 \mathrm{P}$ at $2050^{\circ} \mathrm{C} .^{27}$ Thus, the

Table II. Physical and Mechanical Properties for Alumina Coatings A and B Produced Using SPPS

\begin{tabular}{|c|c|c|c|c|c|c|c|}
\hline \multirow{2}{*}{$\begin{array}{c}\text { Coating } \\
\text { designation }\end{array}$} & \multirow{2}{*}{$\begin{array}{c}\alpha-\mathrm{Al}_{2} \mathrm{O}_{3} \\
\text { content } \\
(\mathrm{wt} \%)\end{array}$} & \multicolumn{2}{|c|}{ Density $\left(\mathrm{g} / \mathrm{cm}^{3}\right)$} & \multicolumn{3}{|c|}{ Porosity $(\%)$} & \multirow{2}{*}{$\begin{array}{c}\text { Flexure } \\
\text { strength } \\
\text { (MPa) }\end{array}$} \\
\hline & & Theoretical & Bulk & Open & Closed & Total & \\
\hline A & $11.0 \pm 0.5$ & 3.69 & $3.26 \pm 0.01$ & 7.5 & 4.0 & 11.5 & $75 \pm 21$ \\
\hline B & $8.1 \pm 0.5$ & 3.68 & $3.33 \pm 0.01$ & 6.8 & 2.6 & 9.4 & $17 \pm 2.4$ \\
\hline
\end{tabular}



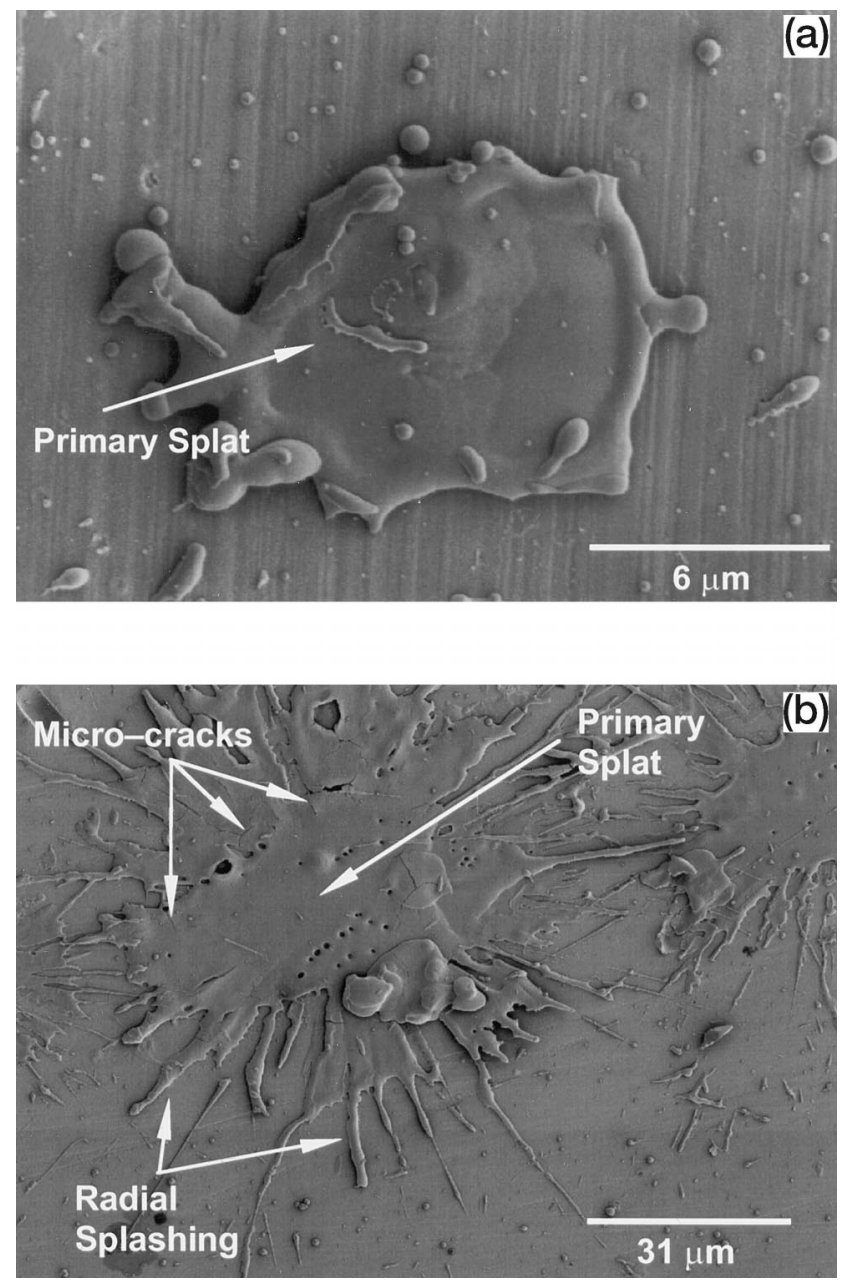

Fig. 2. Comparison of individual splats sprayed with parameters for (a) coating A and (b) coating B. Splats from coating A were typically more coherent and less microcracked, whereas splats from coating B were larger in diameter and exhibited splashing.

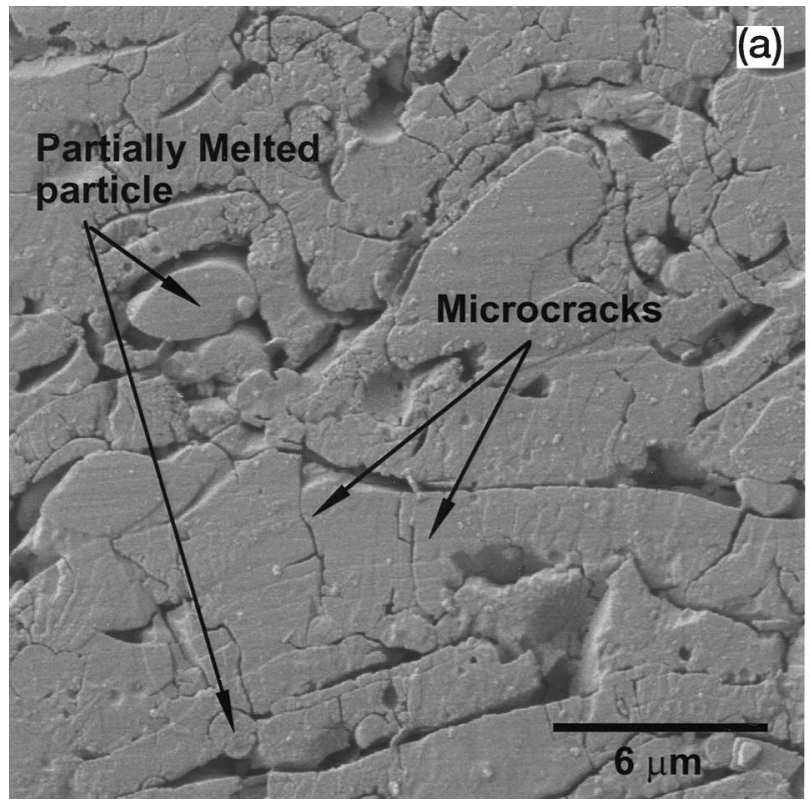

degree of thinning is dependent on the temperature (through the viscosity), the particle size (held constant), and the velocity at impact. Increasing any of these variables will increase the final splat diameter.

Although the material properties defined in Eq. (1) have not been measured in the current work, relative assessments of each can be made based on previously published work. Consideration of the spray parameters used for both coatings (Table I) indicates that coating B would be formed from melted particles that were hotter and had greater velocity at impact. Specifically, the use of more power, ${ }^{10}$ a closer spray distance, and injection into the hotter region of the plume ${ }^{28}$ would result in splats that are formed at a higher temperature than that of splats formed under coating A conditions. During the spraying of coating B, a thermocouple that was mounted behind the substrate revealed it to be $50^{\circ} \mathrm{C}$ hotter than the substrate temperatures that occurred while spraying coating A. The closer spray distance ${ }^{28}$ and increased power would result in a higher velocity at impact for splats that are formed under coating B conditions. Thus, thinner splats would be favored for coating $\mathrm{B}$, in comparison to those for coating $\mathrm{A}$, as observed experimentally.

Re-examination of Fig. 2(b) also reveals splashing of the lamellae, which is indicated by the "stringers" of material that emanate radially from the center of the splat. It has been previously observed that, under certain plasma-spraying conditions, the flattening disk can become unstable and disintegrate at the edge into many small droplets. ${ }^{7,11}$ This process is analogous to the impact of a water droplet on the surface of glass, as studied by Worthington. ${ }^{29}$ Splashing is favored for situations where an increased momentum is imparted to the melted particles or the surface tension of the particles is reduced. Thus, any processing variable that increases either the velocity or temperature of the melted particles will favor splashing. As previously discussed, this situation would be the case for coatings that have been fabricated using the coating $\mathrm{B}$ parameters.

\section{(2) Effect of Splat Geometry on Coating Microstructure}

To evaluate the effect of splat morphology on the subsequent integrity of plasma-sprayed coatings, etched microstructures of coatings $\mathrm{A}$ and $\mathrm{B}$ at identical magnifications were prepared, as shown in Fig. 3. Coating A demonstrated thicker splats, whereas coating B was comprised of highly microcracked thin splats. The observed thinner splats in coating B are consistent with the

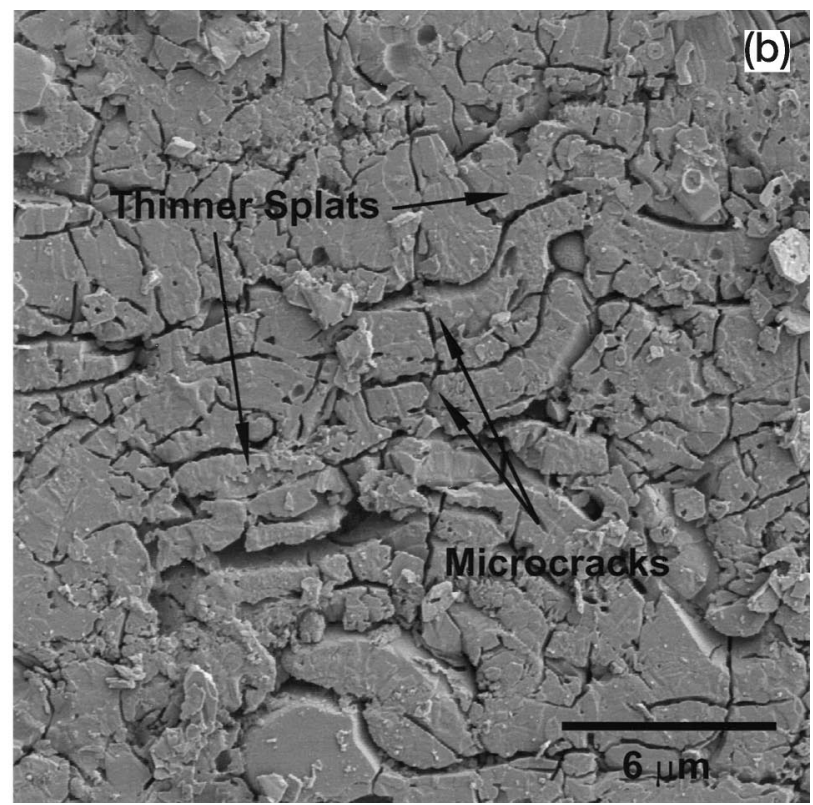

Fig. 3. SEM micrographs of etched SPPS alumina coatings ((a) coating A and (b) coating B). Many of the microstructural features, including grain size, splat boundaries, and unmelted particles, are evident. Closer examination reveals that the coating sprayed with coating B parameters had thinner splats and, therefore, an increased number of splat interfaces. 

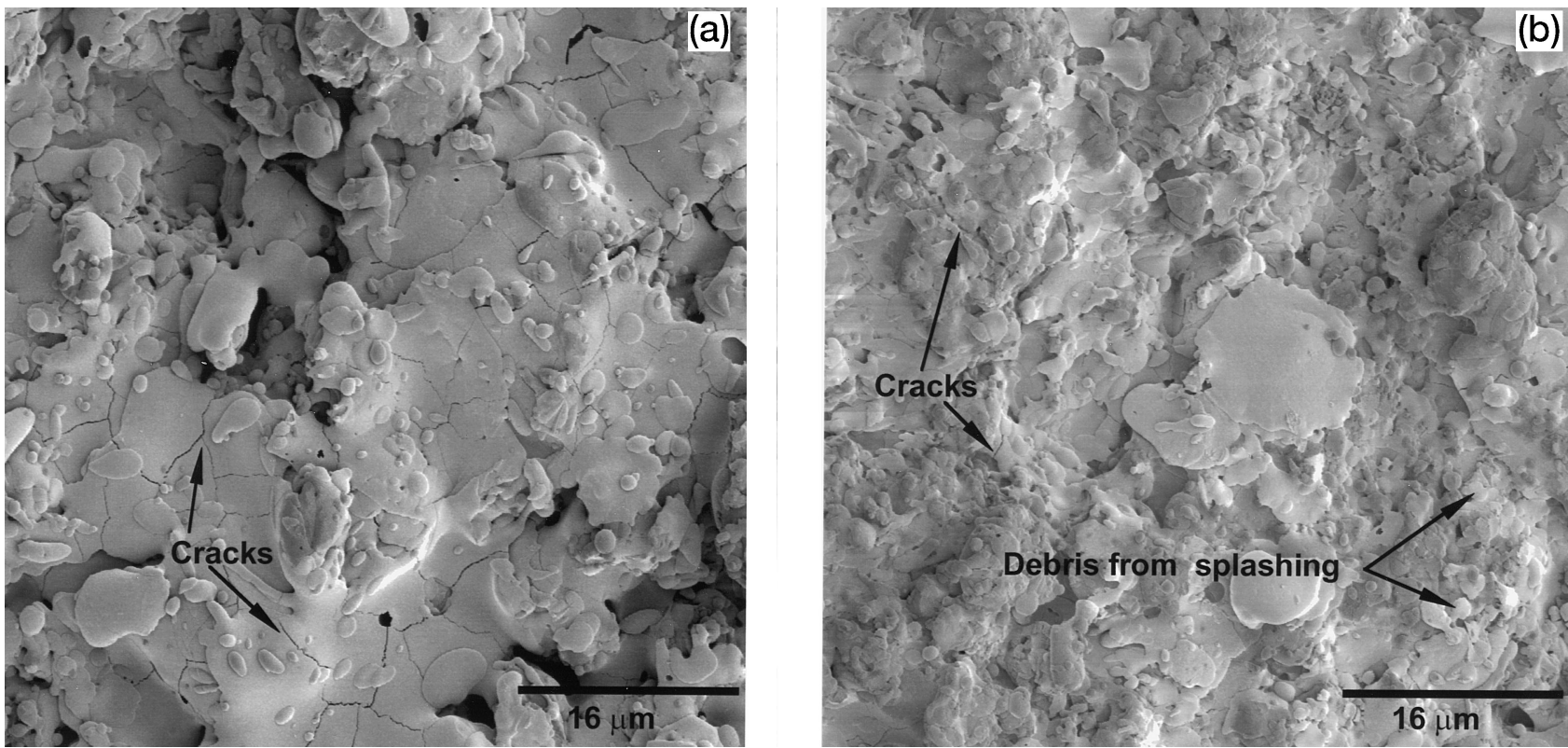

Fig. 4. SEM micrographs showing the top view of (a) coating A and (b) coating B. Thermally generated quench cracks were observed in both coatings; those in coating B are covered by the splashed lamellae and/or debris.

observed larger-diameter lamellae. The hotter spray conditions lead to more quench cracks in coating $\mathrm{B}$, because the residual stresses that develop upon cooling would be greater than those for coating A, because of the larger temperature gradient. As a consequence of the thinner and microcracked splats, more interfaces are observed in coating B than coating A. This difference in microstructure is believed to be responsible for the differences in the penetrability resistance of the two coatings, as measured in a prior study. ${ }^{5}$ Specifically, coating A was immersed in $0.03 \mathrm{M} \mathrm{HCl}$ for $>121 \mathrm{~h}$ without corrosive failure of the underlying substrate. In contrast, coating B only lasted $20 \mathrm{~h}$ before the coating cracked and the substrate began to rust. Thus, coatings that were comprised of the thinner microcracked splats (and the accompanying increase in the number of paths through which liquids could move) resulted in inferior penetrability resistance for coating B.

Fewer partially melted particles were observed in coating B than in coating A. XRD of powder samples of coatings A and B showed that coating $\mathrm{B}$ possessed less $\alpha-\mathrm{Al}_{2} \mathrm{O}_{3}$ than coating $\mathrm{A}$. The presence of $\alpha-\mathrm{Al}_{2} \mathrm{O}_{3}$ is typically attributed to unmelted or partially melted particles, which suggests that the spray conditions used for coating $B$ resulted in increased heating of the powders, relative to the conditions used for coating $\mathrm{A}$, which is consistent with earlier observations.

\section{(3) Effect of Splat Geometry on Surface Roughness}

Figure 4 shows representative top views of coatings A and B. Each coating was the same thickness, $\sim 200 \mu \mathrm{m}$. Large, smooth areas were noted in coating $\mathrm{A}$, which had a surface roughness of $3.8 \pm 0.2 \mu \mathrm{m} \mathrm{rms}{ }^{\ddagger}$ Predominantly rougher areas were observed for coating B (a surface roughness of $5.0 \pm 0.3 \mu \mathrm{m} \mathrm{rms}$ ), with

${ }^{\star}$ Root mean square.

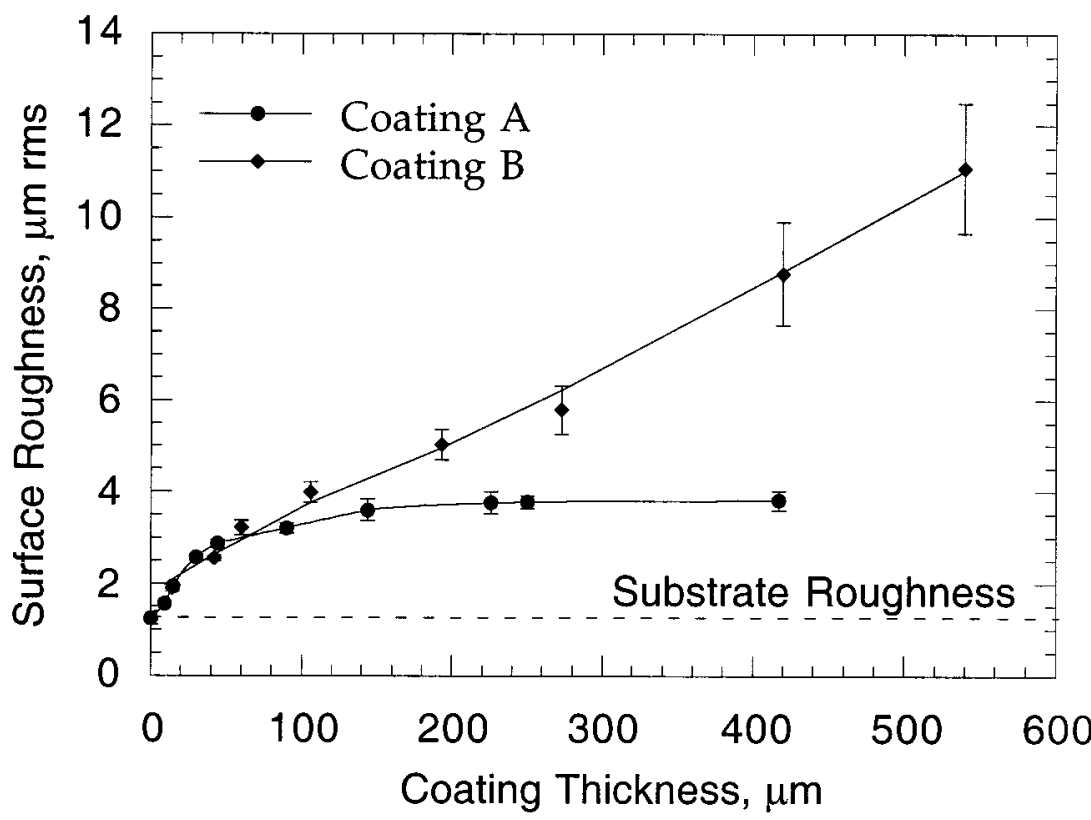

Fig. 5. Effect of coating thickness on the surface roughness of coatings A and B. 
increased debris noted. These microstructural features are consistent with the splashing that is observed in single splats of the material.

During plasma spraying, the surface roughness continually changes with each subsequent pass of the torch. Beginning with a relatively smooth surface of grit-blasted steel $(1.9 \mu \mathrm{m} \mathrm{rms})$, the accumulation of individual splats as they are stacked in succession will alter the surface roughness for the next pass of the torch. Surface roughness has been shown to influence the degree of splashing that is observed in plasma-sprayed coatings. ${ }^{12,13,19,30,31}$ In one paper, Fukanuma ${ }^{19}$ modeled the influence of surface roughness on the final splat geometry. If the impinging velocity is sufficiently great, the melted particle can interact with the surface and splashing can occur as surface asperities scatter the impinging molten drop. Our observations suggest that increasing the population and size of the asperities would further increase the likelihood that an impinging drop would be splashed. The increased number of splashed splats, and the debris they create, then would lead to increased surface roughness, in comparison with unsplashed splat surfaces (compare coatings A and B in Fig. 4).

To investigate the cumulative effects of splashing, plasmasprayed coupons, with coatings ranging in thickness from $20 \mu \mathrm{m}$ to $1.2 \mathrm{~mm}$, were prepared using spray parameters for coatings A and B. Figure 5 shows the effect of coating thickness on the surface roughness for coating thicknesses up to $540 \mu \mathrm{m}$. Coating A quickly plateaued at $3.8 \pm 0.2 \mu \mathrm{m} \mathrm{rms}$, whereas coating B exhibited a linear increase in roughness for thicknesses of $>60$ $\mu \mathrm{m}$. The roughness was $11.1 \pm 1.4 \mu \mathrm{m}$ rms for a coating B thickness of $540 \mu \mathrm{m}$.

The development of a unique surface topology in coating B is responsible for the observed increase in roughness, as shown in Fig. 6 for a 1.2-mm-thick coating. The surface density of these bumps was $\sim 4$ per square millimeter. A cross-sectional view of this 1.2-mm-thick coating (Fig. 7(a)) shows that each surface bump appears as a cone-shaped structure with a definitive starting point. Lines of porosity, which emanated from the base and outlined their cone shape, and a cluster of porosity near their base both were common to all the observed surface bumps. No surface bumps were observed in coating A with a similar coating thickness.

Polished cross sections of different coating thicknesses seem to indicate that small surface perturbations, which first appear for a coating thickness of $\sim 100 \mu \mathrm{m}$, are amplified with each subsequent coating layer, which creates the cone-shaped structure. The physical dimensions of the resulting surface perturbations taken from these micrographs (for example, see Figs. 7(b) and (c)) are plotted in Fig. 8; this figure shows the perturbation height and width, as a

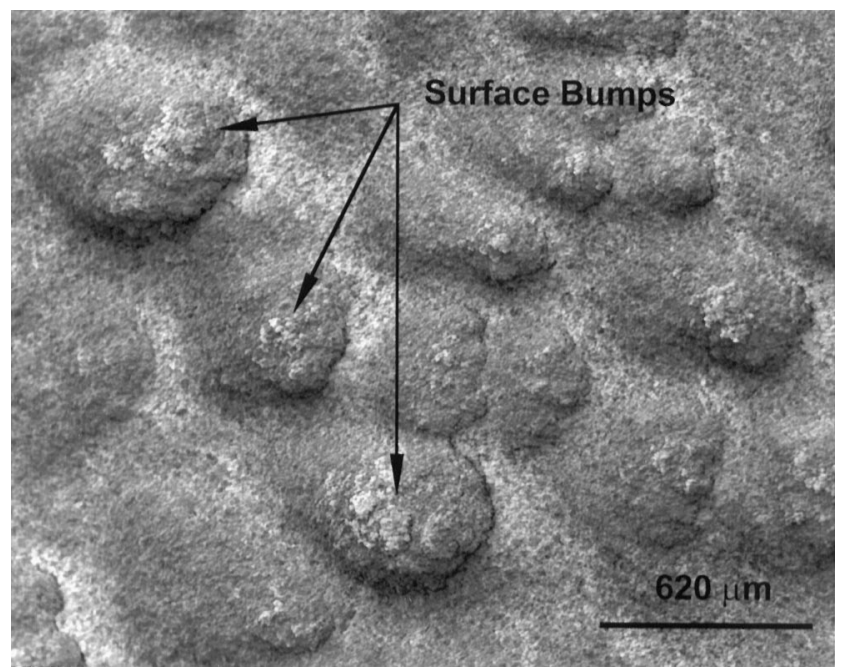

Fig. 6. SEM micrograph of the surface of a 1.2-mm-thick coating sprayed with the coating B spray parameters; the increase in surface roughness with increased coating thickness is due to development of the observed surface bumps.
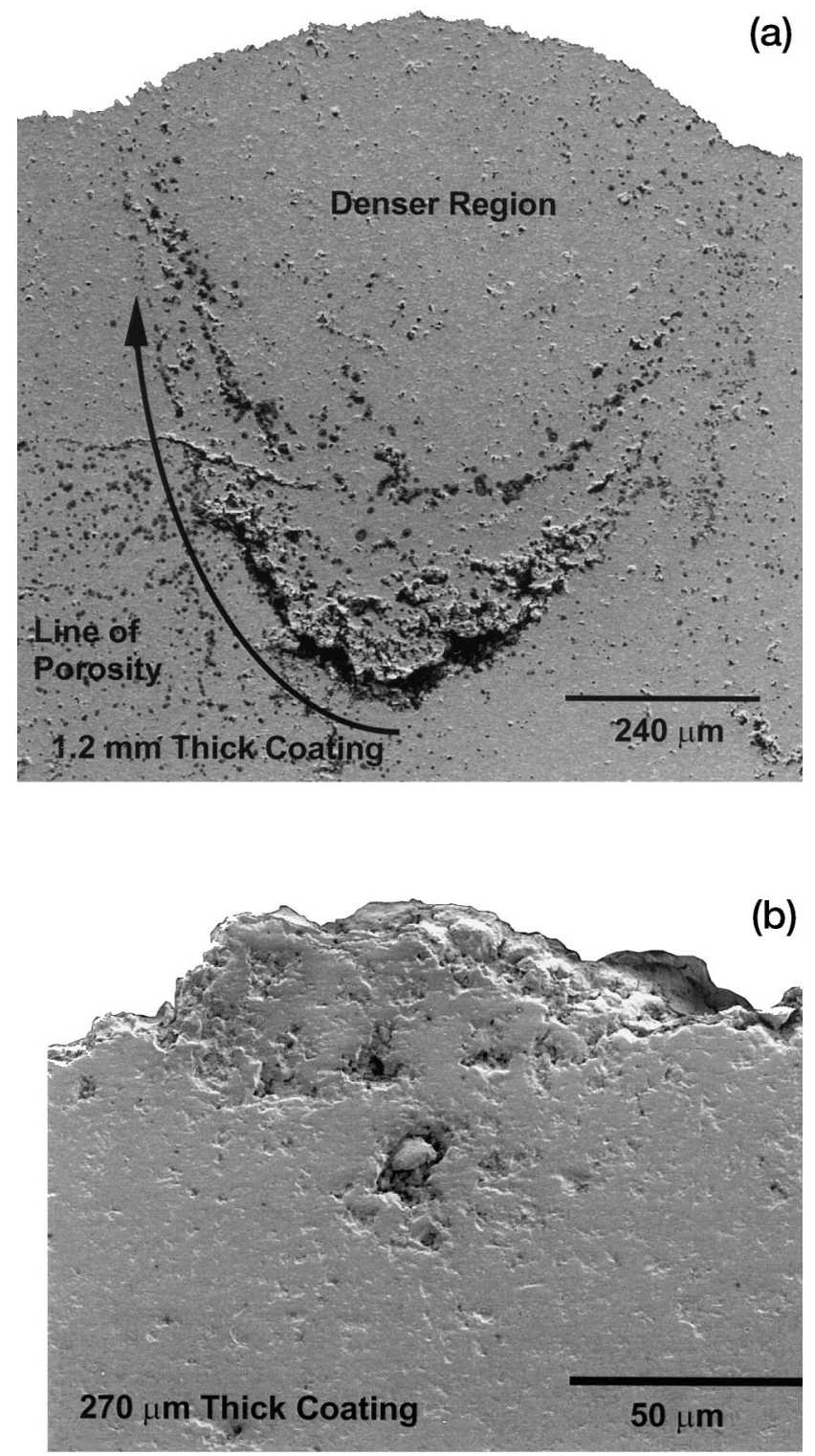

(b)

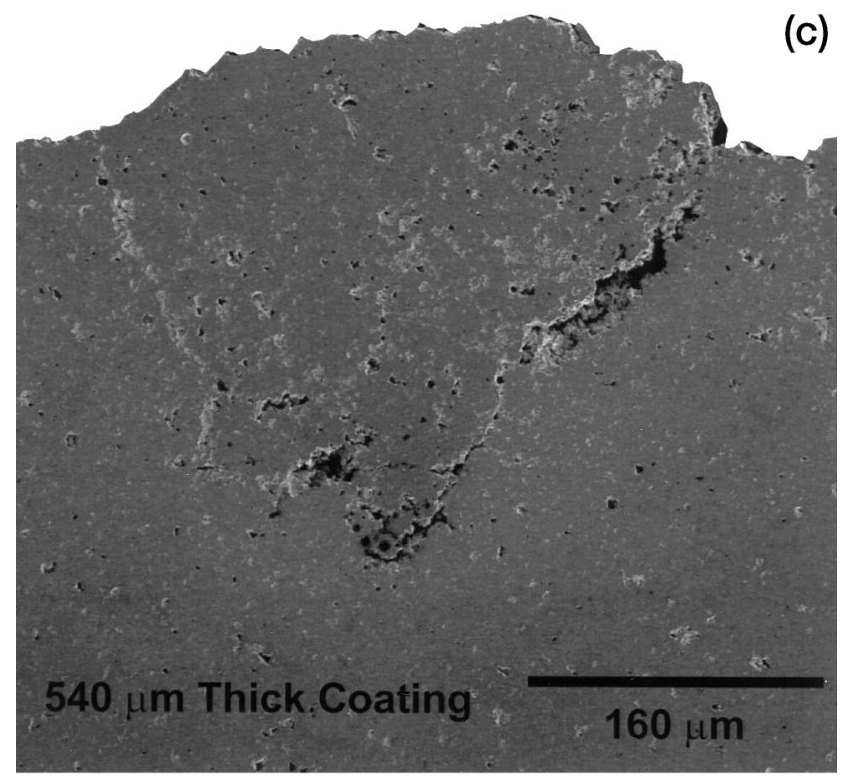

Fig. 7. SEM micrographs of conelike structures at coating thicknesses of (a) $1.2 \mathrm{~mm}$, (b) $270 \mu \mathrm{m}$, and (c) $540 \mu \mathrm{m}$. For thicknesses of up to $1.2 \mathrm{~mm}$, conelike structures were observed only in coating B. 


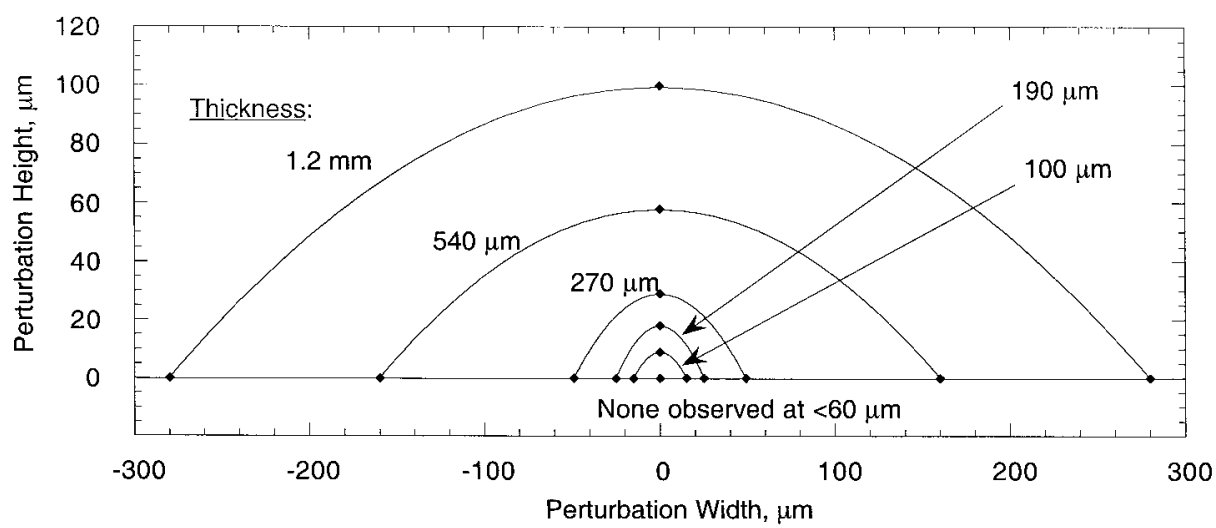

Fig. 8. Development of surface irregularities for coatings processed under coating B conditions versus the coating thickness. No surface perturbations were observed for coatings $60 \mu \mathrm{m}$ thick. Subsequent perturbations that appear at a coating thickness of $100 \mu \mathrm{m}$ were amplified as the coating buildup increased. (The standard deviation for each measurement was $\sim 10 \%$ on both axes.)

function of the coating thickness, and has been fit with a smooth function. Each data point is based on an average of three measurements. For example, at a coating thickness of $540 \mu \mathrm{m}$, the surface bumps exhibited a height of $60 \mu \mathrm{m}$ and a width of $320 \mu \mathrm{m}$. A size distribution of the surface bumps was observed, and Fig. 8 was generated from the larger surface perturbations. Figure 8 clearly shows that a critical-size perturbation (a height of $\sim 10 \mu \mathrm{m}$ ) is necessary for the development and growth of a surface bump. Interestingly, the development of the critical-size perturbation began at the same thickness $(\sim 100 \mu \mathrm{m})$ as that at which the roughness of coating B began to exceed the roughness of coating A (see Fig. 5).

What role, if any, does changing spray parameters have in generating critical-size surface perturbations? Investigation of every surface irregularity revealed the presence of appreciable porosity near the base of the cone-shaped entity, as is evident in Fig. 7(a). In this study, the cumulative buildup of layers of splashed particles is proposed to result in the critically sized surface perturbations that eventually lead to the large surface bumps.

The suggested mechanism for the growth of perturbations into the large surface bumps is illustrated in Fig. 9. Beginning with a small surface perturbation, subsequent interactions of the incoming melted particles with this perturbation are suggested to create large, porous regions, because of localized splat disorder. Subsequent interactions of the incoming melted particles with these regions are believed to create more porosity, which results in growth of the perturbation. The splat/perturbation interaction is repeated with each subsequent pass of the torch, which creates more porosity and forms the base and porosity lines of the cone-shaped bump. Next, dense regions begin to develop in the middle of the bump, because of a decrease in its radius of curvature, as indicated in Fig. 7(a). However, the edge between the smooth coating and the emerging bump is proposed to act as a shield to incoming melted particles, which generates the observed porosity lines. The porosity lines extend outward, because the width of the surface bump increases with each pass of the torch.

\section{(4) Effect of Splat Morphology on Mechanical Strength}

One requirement for protective coatings is the ability to remain attached to the substrate during normal use. Thus, a coating must demonstrate a sufficient strain-to-failure to remain uncracked and adhere to the substrate. The mechanical strength of plasma-sprayed coatings is governed by the same parameters that govern the strength of monolithic ceramics: primarily, the flaw size and population. Figure 3 shows that the plasma-sprayed coatings were composed of thin, stacked lamellae. Several types of flaws can be formed easily as each splat is cooled below its melting temperature before the torch sprays another layer. Macroporosity (1-5 $\mu \mathrm{m})$ typically occurs because of the subsequent stacking of splats on partially or unmelted particles. This large-scale porosity also can
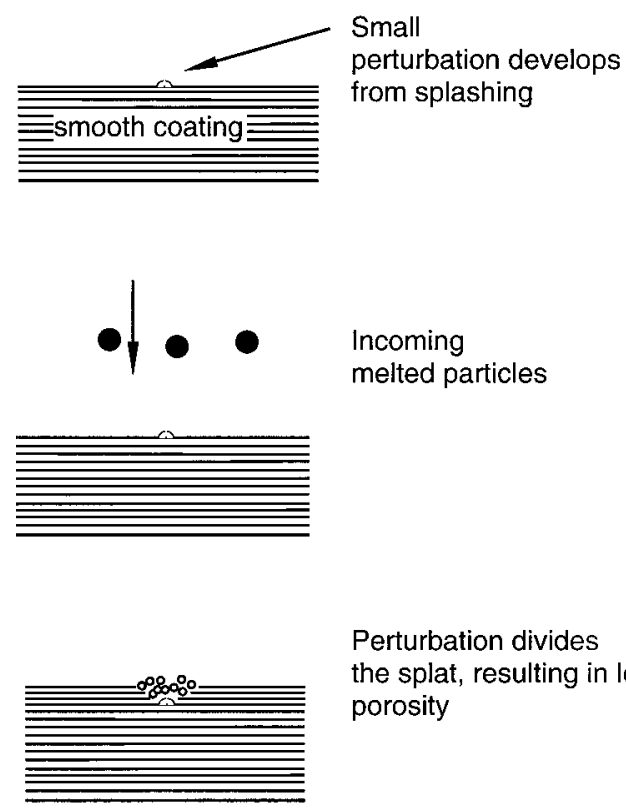

Perturbation divides

the splat, resulting in localized porosity
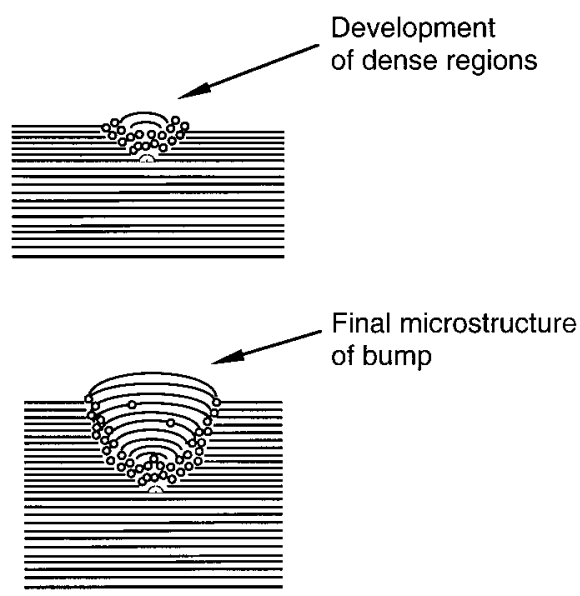

Fig. 9. Suggested mechanism for the development of the unique microstructure observed in coating B. Porosity that develops due to splashing of the molten particles is believed to cause critical-sized surface perturbations that, in turn, affect the buildup of the resulting layers. 

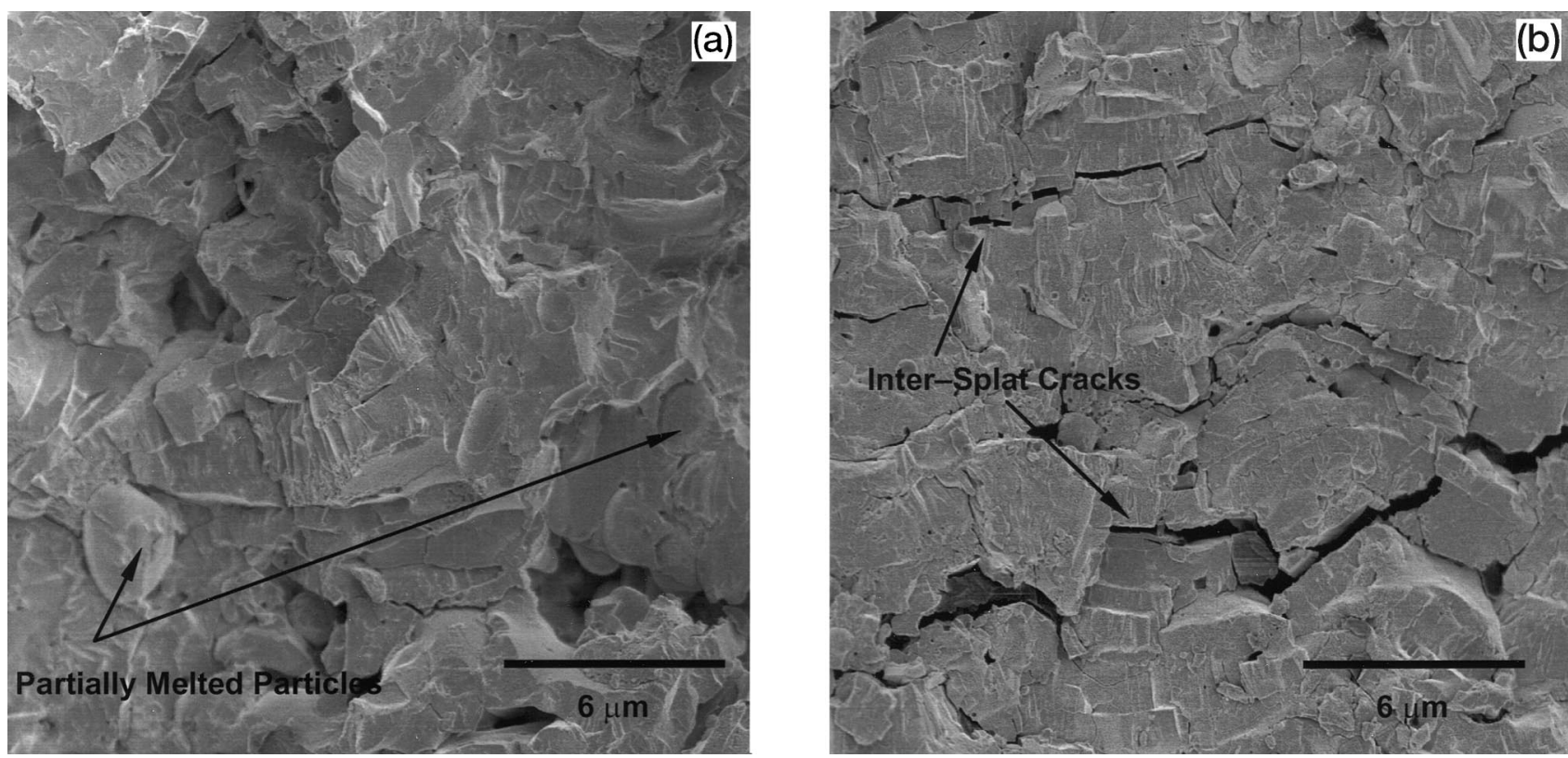

Fig. 10. SEM micrographs showing the failure surfaces of (a) coating A and (b) coating B tested in flexure.

form because of inefficient stacking of lamellae, as a result of particle splashing (see Fig. 7(a)). Microporosity, with pores that are typically $0.1 \mu \mathrm{m}$ in size, occurs between individual lamellae. ${ }^{32}$ This type of porosity has been observed in SPPS alumina. ${ }^{33}$ In addition to porosity, cracks that form because of residual stresses often are formed upon cooling (see Figs. 2-4). ${ }^{34}$

The alignment of these defects, with respect to the applied tensile stress, will influence the degree to which they influence strength. Pure tension is observed on the outer surface between the inner loading pins of a four-point bend bar. Defects that are oriented perpendicular to this stress will act as stress concentrations, which often drastically reduce the failure stress. In plasmasprayed coatings, adjacent lamellae within the plane of spraying and quench cracks are oriented perpendicular to the tensile stresses.

The flexure strength of coatings A and B in the as-sprayed condition are given in Table II. Coating A possessed a strength of $75 \pm 21 \mathrm{MPa}$, which is approximately twice the strength of traditionally plasma-sprayed alumina. ${ }^{35}$ Dense, hot-pressed alumina, with a grain size similar to that observed in SPPS alumina, has a strength of $600 \pm 100 \mathrm{MPa}^{36}$ Thus, coating $\mathrm{A}$ is approximately one-eighth the strength of fully dense alumina.

The strength of a porous bulk ceramic has been estimated empirically as ${ }^{37}$

$$
\sigma=\sigma_{0} \exp (-n P)
$$

where $\sigma_{0}$ is the pore-free strength and $P$ is the volume fraction of pores. The variable $n$ is determined empirically and has a value of $4-7$. If the value of $\sigma_{0}$ is assumed to be $600 \mathrm{MPa}$, the strength of alumina with 11 vol\% porosity (similar to coating A presently studied) is $\sim 300-350 \mathrm{MPa}$. Thus, porosity alone cannot account for the measured strength reduction of SPPS alumina. Therefore, the role of quench cracks, as observed in Fig. 4, must be considered to be very important in influencing the strength in SPPS coatings.

The flexural strength of coating B was $17 \pm 2.4 \mathrm{MPa}$, which is much less than that measured for coating A. Comparison of the failure surfaces for both coatings, as shown in Fig. 10, reveals the reasons for these differences. The fracture surface of coating A was typically rough and free of large, continuous cracks. Relatively smooth fracture surfaces were observed in coating B. It is proposed that the porosity lines that are observed in coating B would provide a weak path for crack propagation and result in the observed smooth fracture surface. Large delamination cracks also were observed running between splats; however, the role they would have in the flexure strength of coating B is unclear, because they would be oriented parallel to the applied loading during testing.

\section{Conclusions}

Spray parameters significantly influence the microstructure of plasma-sprayed coatings by altering the geometry of individual splats. Splashing, which is a process that occurs when the individual melted particle disintegrates at its edges during its collision with the substrate or previously sprayed splats, has been shown to occur in small-particle plasma-spray alumina (SPPS alumina) under specific conditions. This phenomenon is influenced by the temperature of the melted particle (through its viscosity) and its velocity. Microstructures that are comprised of splashed lamellae have thinner splat sizes and more quench cracks, develop unique surface features that result in increased roughness, and are mechanically inferior to coatings made from nonsplashed lamellae. In conclusion, the nature and degree of microstructural defects can be controlled by carefully monitoring and controlling the processing parameters that determine both the viscosity and the velocity of the melted particles. Understanding this processstructure relationship is essential to developing high-quality coatings.

\section{Acknowledgments}

The authors wish to thank Rick Marzec for preparing the plasma-sprayed coatings. Tom Easley, Don Baskin, Jennifer Mawdsley, Jennifer Su, and Dr. Tom Bernecki, who also provided valuable input to this manuscript, are acknowledged.

\section{References}

K. Legg and T. Bernecki, "Environmentally Compliant Coatings for Wear and Corrosion Control," Progress Report for AFOSR Contract No. F49620-96-1-0298, Sept. 1, 1996-Aug. 31, 1997

${ }^{2}$ H. M. Hawthorne, L. C. Erickson, D. Ross, H. Tai, and T. Troczynski, "The Microstructural Dependence of Wear and Indentation Behavior of Some PlasmaSprayed Alumina Coatings," Wear, 203 [204] 706-14 (1997).

${ }^{3}$ K. Niemi, P. Vuoristo, and T. Mantyla, "Properties of Alumina-Based Coatings Deposited by Plasma Spray and Detonation Gun Spray Processes," J. Therm. Spray Technol., 3 [2] 199-203 (1994).

${ }^{4}$ T. F. Bernecki and D. R. Marron, "Small Particle Plasma Spray Apparatus, Method and Coated Article," U.S. Pat. No. 5744 777, April 28, 1998.

${ }^{5}$ Y. J. Su and J. Mawdsley, Northwestern University, Evanston, IL; personal communication. 
${ }^{6} \mathrm{~J}$. Madjeski, "Solidification of Droplets on a Cold Surface," Int. J. Heat Mass Transfer, 19, 1009-13 (1976).

${ }^{7}$ R. McPherson, "The Relationship Between the Mechanism of Formation, Microstructure and Properties of Plasma-Sprayed Coatings," Thin Solid Films, 83, 297-310 (1981).

${ }^{8}$ M. Pasandideh-Fard and J. Mostaghimi, "Droplet Impact and Solidification in a Thermal Spray Process: Droplet-Substrate Interactions"; pp. 637-46 in Thermal Spray: Practical Solutions for Engineering Problems. Edited by C. C. Berndt. ASM International, Materials Park, OH, 1996.

${ }^{9}$ L. Bianchi, P. Lucchese, A. Denoirjean, and P. Fauchais, "Microstructural Investigation of Plasma-Sprayed Alumina Splats"; pp. 255-60 in Advances in Thermal Spray Science and Technology. Edited by C. C. Berndt and S. Sampath. ASM International, Materials Park, OH, 1995.

${ }^{10} \mathrm{P}$. Fauchais, J. F. Coudert, A. Vardell, M. Vardelle, A. Grimaud, and P. Roumilhas, "State of the Art for the Understanding of the Physical Phenomena Involved in Plasma Spraying at Atmospheric Pressure"; pp. 11-19 in Thermal Spray: Advances in Coatings Technology. Edited by D. L. Houch. ASM International, Materials Park, OH, 1988.

${ }^{11}$ H. Liu, E. J. Lavernia, R. H. Rangel, E. Muehlberger, and A. Sickinger, "Deformation and Interaction Behavior of Molten Droplets Impinging on a Flat Substrate in Plasma Spray Process"; pp. 457-62 in Thermal Spray Coatings: Research, Design and Applications. Edited by C. C. Berndt and T. F. Bernecki. ASM International, Materials Park, OH, 1993.

${ }^{12}$ C. Moreau, P. Gougeon, and M. Lamontagne, "Influence of Substrate Preparation on the Flattening and Cooling of Plasma-Sprayed Particles," J. Therm. Spray Technol., 4 [1] 25-33 (1995).

${ }^{13}$ L. Bianchi, A. Grimaud, F. Blein, P. Lucchese, and P. Fauchais, "Comparison of Plasma-Sprayed Alumina Coatings by RF and DC Plasma Spraying," J. Therm. Spray Technol., 4 [1] 59-65 (1995).

${ }^{14}$ S. Fantassi, M. Vardelle, A. Vardelle, and P. Fauchais, "Influence of the Velocity of Plasma Sprayed Particles on the Splat Formation"; see Ref. 11, pp. 1-6.

${ }^{15}$ L. Bianchi, P. Lucchese, A. Denoirjean, and P. Fauchais, "Zirconia Splat Formation and Resulting Coating Properties"; see Ref. 9, pp. 261-66.

${ }^{16}$ M. Vardelle, A. Vardelle, A. C. Leger, P. Fauchais, and D. Gobin, "Influence of Particle Parameters at Impact on Splat Formation and Solidification in PlasmaSpraying Process," J. Therm. Spray Technol., 4 [1] 50-58 (1995).

${ }^{17} \mathrm{C} . \mathrm{Li}, \mathrm{A}$. Ohmori, and Y. Harada, "Experimental Investigation of the Morphology of Plasma-Sprayed Copper Splats"; pp. 333-39 in Proceedings of the 14th International Thermal Spray Conferences, Thermal Spraying: Current Status and Future Trends (May 1995, Kobe, Japan). Edited by A. Ohmori. High Temperature Society of Japan, Osaka, Japan, 1995.

${ }^{18}$ S. J. Yankee and B. J. Pletka, "Effect of Plasma-Spray Processing Variations on Particle Melting and Splat Spreading of Hydroxylapatite and Alumina," J. Therm. Spray Technol., 2 [3] 271-81 (1993).

${ }^{19}$ H. Fukanuma, "Mathematical Modeling of Flattening Process on Rough Surfaces in Thermal Spray"; see Ref. 8, pp. 647-56.
${ }^{20}$ A. Haddadi, F. Nardou, A. Grimaud, and P. Fauchais, "Generation of the First Layers of Zirconia Plasma-Sprayed Coating: Correlation between Splat Layering and Spray Parameters"; see Ref. 9, pp. 249-54.

${ }^{21}$ A. C. Leger, M. Vardelle, A. Vardelle, P. Fauchais, S. Sampath, C. C. Berndt, and H. Herman, "Plasma-Sprayed Zirconia: Relationships between Particle Parameters, Splat Formation and Deposit Generation-Part I: Impact and Solidification"; see Ref. 8, pp. 623-28.

${ }^{22}$ R. Bhola and S. Chandra, "Splat Solidification of Tin Droplets"; see Ref. 8, pp. $657-63$.

${ }^{23}$ G. Montavon, S. Sampath, C. C. Berndt, H. Herman, and C. Coddet, "Effects of the Substrate Nature on the Splat Morphology of Vacuum Plasma-Sprayed Deposits"; see Ref. 17, pp. 365-70.

${ }^{24}$ S. Sampath, J. Matejicek, C. C. Berndt, H. Herman, A. C. Leger, M. Vardelle, A. Vardelle, and P. Fauchais, "Plasma-Sprayed Zirconia: Relationships among Particle Parameters, Splat Formation and Deposit Generation-Part II: Microstructure and Properties"; see Ref. 8, pp. 629-36.

25"Standard Test Method for Water Absorption, Bulk Density, Apparent Porosity, and Apparent Specific Gravity of Fired Whiteware Products," ASTM Standard C 373-72, 1982 ASTM Annual Book of Standards. American Society for Testing and Materials, West Conshohocken, PA.

${ }^{26}$ H. P. Klug and L. E. Alexander, X-ray Diffraction Procedures; pp. 531-38. Wiley, New York, 1974

${ }^{27}$ R. McPherson, "On the Formation of Thermally Sprayed Alumina Coatings," $J$. Mater. Sci., 15, 3141-49 (1980).

${ }^{28}$ N. El-Kaddah, J. McKelliget, and J. Szekely, "Heat Transfer and Fluid Flow in Plasma Spraying," Metall. Trans. B, 15B [3] 59-70 (1984).

${ }^{29}$ A. M. Worthington, A Study of Splashes. Macmillan, New York, 1963.

${ }^{30}$ A. C. Leger, M. Vardelle, A. Vardelle, B. Dussoubs, and P. Fauchais, "Splat Formation: Ceramic Particles on Ceramic Substrates"; see Ref. 9, pp. 169-74.

${ }^{31}$ M. F. Smith, R. A. Neiser, and R. C. Dykhuizen, "An Investigation of the Effects of Droplet Impact Angle in Thermal Spray Deposition"; pp. 603-608 in Thermal Spray Industrial Applications. Edited by C. C. Berndt and S. Sampath. ASM International, Materials Park, OH, 1994

${ }^{32} \mathrm{R}$. McPherson, "A Review of Microstructure and Properties of Plasma-Sprayed Ceramic Coatings," Surf. Coat. Technol., 39/40, 173-81 (1989).

${ }^{33}$ A. R. de Arellano-López and K. T. Faber, "Microstructural Characterization of Small-Particle Plasma-Spray Coatings," J. Am. Ceram. Soc., 82 [8] 2204-208 (1999).

${ }^{34}$ S. Kuroda and T. W. Clynne, "The Quenching Stress in Thermally Sprayed Coatings," Thin Solid Films, 200, 49-66 (1991).

${ }^{35}$ E. H. Lutz, "Microstructure and Properties of Plasma Ceramics," J. Am. Ceram. Soc., 77 [5] 1274-80 (1994).

${ }^{36}$ J.B. Wachtman, Mechanical Properties of Ceramics; p. 358. Wiley Interscience, New York, 1996.

${ }^{37}$ W. Duckworth, "In Response to "Compression Strength of Porous Sintered Alumina and Zirconia'," J. Am. Ceram. Soc., 36 [2] 65-68 (1953). 